\title{
Synthesis of hydrogenated diamondlike carbon thin films using neon-acetylene based high power impulse magnetron sputtering discharges
}

Asim AijazSascha LouringDaniel LundinTomáš KubartJens Jensen, Kostas Sarakinos, and Ulf Helmersson

Citation: Journal of Vacuum Science \& Technology A: Vacuum, Surfaces, and Films 34, 061504 (2016); doi: 10.1116/1.4964749

View online: $\mathrm{http}: / / \mathrm{dx}$. doi.org/10.1116/1.4964749

View Table of Contents: http://avs.scitation.org/toc/jva/34/6

Published by the American Vacuum Society

\section{Articles you may be interested in}

Target poisoning during $\mathrm{CrN}$ deposition by mixed high power impulse magnetron sputtering and unbalanced magnetron sputtering technique

Journal of Vacuum Science \& Technology A: Vacuum, Surfaces, and Films 34, 041502041502 (2016);

$10.1116 / 1.4950886$

Low electrical resistivity in thin and ultrathin copper layers grown by high power impulse magnetron sputtering Journal of Vacuum Science \& Technology A: Vacuum, Surfaces, and Films 34, 051506051506 (2016);

10.1116/1.4959555

Sputtering process in the presence of plasma self-organization

Journal of Vacuum Science \& Technology A: Vacuum, Surfaces, and Films 110, 014103014103 (2017);

$10.1063 / 1.4973643$

w www.HidenAnalytical.com

E info@hiden.co.uk

CLICK TO VIEW our product catalogue

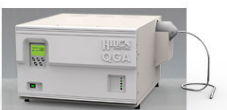

Gas Analysis

- dynamic measurement of reaction gas streams cataysis and thermal analysis

- molecuar beam studes

dissolved speces probe

fermentation, envirormental and ecological studies

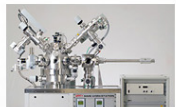

Surface Science

UHVTPD

,end point detection in in beam etch , elemental imaging-surface mapping

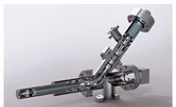

Plasma Diagnostics

, plasma source characterization etch and deposition process reaction kinetic studies

analysis of neutral and radical species

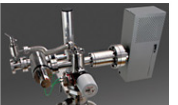

Vacuum Analysis partial pressure measurement and control of process gases reactive sputter process control vacuum diagnostics 


\title{
Synthesis of hydrogenated diamondlike carbon thin films using neon-acetylene based high power impulse magnetron sputtering discharges
}

\author{
Asim Aijaz ${ }^{\text {a) }}$ \\ Department of Physics, Chemistry and Biology, IFM-Material Physics, Linköping University, SE-581 83 \\ Linköping, Sweden and Department of Engineering Sciences, The Angström Laboratory, \\ Uppsala University, P.O. Box 534, SE-751 21 Uppsala, Sweden
}

\author{
Sascha Louring \\ Interdisciplinary Nanoscience Center (iNANO), Aarhus University, Ny Munkegade 120, 8000 Aarhus C, \\ Denmark and Tribology Centre, Danish Technological Institute, Teknologiparken, Kongsvang Allé 29, \\ DK-8000 Aarhus C, Denmark \\ Daniel Lundin \\ Laboratoire de Physique des Gaz et Plasmas-LPGP, UMR 8578 CNRS, Université Paris-Sud, \\ Université Paris-Saclay, 91405 Orsay Cedex, France \\ Tomáš Kubart \\ Department of Engineering Sciences, The Angström Laboratory, Uppsala University, P.O. Box 534, \\ SE-751 21 Uppsala, Sweden \\ Jens Jensen, Kostas Sarakinos, and Ulf Helmersson \\ Department of Physics, Chemistry and Biology, IFM-Material Physics, Linköping University, \\ SE-581 83 Linköping, Sweden
}

(Received 7 July 2016; accepted 27 September 2016; published 10 October 2016)

\begin{abstract}
Hydrogenated diamondlike carbon (DLC:H) thin films exhibit many interesting properties that can be tailored by controlling the composition and energy of the vapor fluxes used for their synthesis. This control can be facilitated by high electron density and/or high electron temperature plasmas that allow one to effectively tune the gas and surface chemistry during film growth, as well as the degree of ionization of the film forming species. The authors have recently demonstrated by adding $\mathrm{Ne}$ in an Ar-C high power impulse magnetron sputtering (HiPIMS) discharge that electron temperatures can be effectively increased to substantially ionize $\mathrm{C}$ species [Aijaz et al., Diamond Relat. Mater. 23, 1 (2012)]. The authors also developed an $\mathrm{Ar}-\mathrm{C}_{2} \mathrm{H}_{2}$ HiPIMS process in which the high electron densities provided by the HiPIMS operation mode enhance gas phase dissociation reactions enabling control of the plasma and growth chemistry [Aijaz et al., Diamond Relat. Mater. 44, 117 (2014)]. Seeking to further enhance electron temperature and thereby promote electron impact induced interactions, control plasma chemical reaction pathways, and tune the resulting film properties, in this work, the authors synthesize DLC:H thin films by admixing Ne in a HiPIMS based $\mathrm{Ar} / \mathrm{C}_{2} \mathrm{H}_{2}$ discharge. The authors investigate the plasma properties and discharge characteristics by measuring electron energy distributions as well as by studying discharge current characteristics showing an electron temperature enhancement in $\mathrm{C}_{2} \mathrm{H}_{2}$ based discharges and the role of ionic contribution to the film growth. These discharge conditions allow for the growth of thick $(>1 \mu \mathrm{m})$ DLC:H thin films exhibiting low compressive stresses $(\sim 0.5 \mathrm{GPa})$, high hardness $(\sim 25 \mathrm{GPa})$, low $\mathrm{H}$ content $(\sim 11 \%)$, and density in the order of $2.2 \mathrm{~g} / \mathrm{cm}^{3}$. The authors also show that film densification and change of mechanical properties are related to $\mathrm{H}$ removal by ion bombardment rather than subplantation. @ 2016 American Vacuum Society. [http://dx.doi.org/10.1116/1.4964749]
\end{abstract}

\section{INTRODUCTION}

Hydrogenated diamondlike carbon (DLC:H) thin films exhibit a wide range of properties such as low friction coefficient, chemical inertness, high refractive index, etc., ${ }^{1,2}$ which make them attractive for a number of industrial applications. ${ }^{1,2}$ The properties of DLC:H depend on their structure, bonding configuration $\left(\mathrm{sp}^{3} / \mathrm{sp}^{2}\right.$ fraction), and chemical composition ( $\mathrm{H}$ content). ${ }^{2}$ These properties can be tailored by controlling energy and composition of the film forming flux.

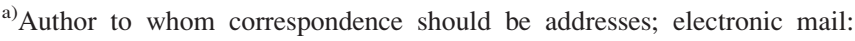
asim.aijaz@angstrom.uu.se
}

This can be, in turn, facilitated by high electron density and electron temperature based plasma processes that allow one to effectively control the plasma and growth chemistry by generating large amount of ionized species. Examples of such processes include filtered cathodic vacuum arc, pulsed laser deposition (PLD), plasma-enhanced chemical vapor deposition (PECVD) and high power impulse magnetron sputtering (HiPIMS). ${ }^{2-9}$

HiPIMS operates at $2-3$ orders of magnitude higher plasma density as compared to standard direct current magnetron sputtering which facilitates the generation of large ionized fraction of the deposition species. ${ }^{10-12}$ Moreover, owing to the fact that it is based on magnetron sputtering, ${ }^{10-12}$ HiPIMS 
is an industrially relevant method for large scale production of coatings. The potential of HiPIMS has been explored for the production of DLC thin films by several authors and it has shown promising results. ${ }^{13-18}$ However, conventional Ar-C HiPIMS discharges have been found to exhibit significantly smaller degree of ionization of sputtered material ${ }^{14}$ as opposed to their Ar-metal counterparts ${ }^{19,20}$ rendering HiPIMS insufficient for synthesizing high quality DLC films. We have recently addressed this challenge ${ }^{21}$ by developing a novel Nebased HiPIMS process; the presence of $\mathrm{Ne}$ as a sputtering gas resulted in a substantial increase of the electron temperature as compared to Ar-based HiPIMS process. This led to the generation of large ionized fraction of $\mathrm{C}$ with relatively high $\mathrm{C}$ ion energies allowing for the growth of ultradense, hydrogen free DLC thin films. In particular, DLC films with mass densities in the order of $2.8 \mathrm{~g} / \mathrm{cm}^{3}$ were synthesized which are close to the best films obtained using state-of-the art methods for DLC production, for example, the PLD process.

We also explored a HiPIMS-based route for high-rate synthesis of dense and hard hydrogenated DLC thin films by admixing $\mathrm{C}_{2} \mathrm{H}_{2}$ into Ar ambient. ${ }^{22}$ The presence of $\mathrm{C}_{2} \mathrm{H}_{2}$ introduced additional interactions of plasma electrons leading to dissociation and ionization of $\mathrm{C}_{2} \mathrm{H}_{2}$ along with the interactions of plasma electrons with the buffer gas and sputtered C. This process facilitated an increased amount of deposited $\mathrm{C}$ (tenfold increased deposition rates), and the resulting films exhibited hardness higher than $25 \mathrm{GPa}$ and mass densities in the order of $2.32 \mathrm{~g} / \mathrm{cm}^{3}$. The promising prospect of the resulting DLC:H films was their low $\mathrm{H}$ content which did not exceed 10 at. \%. Such a low H content together with a hardness in the order of $25 \mathrm{GPa}$ and significantly high deposition rates are promising since a hydrocarbon based process (including magnetron sputtering and PECVD) typically results in $\mathrm{H}$ contents above 20 at. $\%$ and hardness in the range of $10-15 \mathrm{GPa}^{2,5}$

In the present work, we are adding $\mathrm{Ne}$ to the $\mathrm{Ar} / \mathrm{C}_{2} \mathrm{H}_{2}$ HiPIMS discharge, which may facilitate an increased electron temperature, and hence increased ionization of depositing species, similar to our previous work in $\mathrm{Ne}+\mathrm{Ar}$ discharges. ${ }^{21}$ We synthesize thin films using $\mathrm{Ne}+$ Ar based $\mathrm{C}_{2} \mathrm{H}_{2}$ process and investigate the correlation between plasma and film properties. In order to elucidate the effect of admixing $\mathrm{Ne}$ in $\mathrm{Ar}$ and $\mathrm{Ar} / \mathrm{C}_{2} \mathrm{H}_{2}$ atmosphere, we also compare the resulting film properties with our previous studies. ${ }^{21,22}$ The plasma properties are investigated by measuring electron energy distribution functions (EEDF) (thereby determining electron temperature and electron density from EEDF), which, contrary to our expectations, shows that higher electron temperatures are obtained when the process gas $(\mathrm{Ne}+\mathrm{Ar})$ contains $\mathrm{C}_{2} \mathrm{H}_{2}$. The plasma properties are also investigated by studying the behavior of the discharge current under different gas phase composition. It is found that larger peak currents indicating the presence of larger amounts of ions are obtained for $\mathrm{Ne}+\mathrm{Ar} / \mathrm{C}_{2} \mathrm{H}_{2}$ discharge as compared to $\mathrm{Ne}+\mathrm{Ar}$ discharge. The correlation between the plasma properties and the resulting thin films is studied by investigating the chemical composition, structural (mass density and bond configuration), and mechanical (hardness and compressive stresses) properties of the films. It is shown that the film densification (and corresponding increase in film hardness) is caused by $\mathrm{H}$ removal rather than subplantation of $\mathrm{C}$.

\section{EXPERIMENTAL DETAILS}

Experiments were performed in a stainless steel vacuum chamber $420 \mathrm{~mm}$ in diameter and $300 \mathrm{~mm}$ in height that was evacuated to a base pressure below $2 \times 10^{-4} \mathrm{~Pa}$. A carbon disk $50 \mathrm{~mm}$ in diameter and $3 \mathrm{~mm}$ in thickness (purity 99.9\%) was used as a sputtering target, which was mounted on a circular unbalanced magnetron. Plasma discharges were obtained using a mixed $\mathrm{Ne}, \mathrm{Ar}$, and $\mathrm{C}_{2} \mathrm{H}_{2}$ ambient under two different conditions; (1) using a gas mixture consisting of $62 \% \mathrm{Ne}, 36 \% \mathrm{Ar}$, and $2 \% \mathrm{C}_{2} \mathrm{H}_{2}$ at a total pressure of $2 \mathrm{~Pa}$ and (2) using a gas mixture consisting of $83 \% \mathrm{Ne}, 15 \% \mathrm{Ar}$, and $2 \% \mathrm{C}_{2} \mathrm{H}_{2}$ at a total pressure of $3.3 \mathrm{~Pa}$ where the gas fractions used in (1) and (2) are in pressure \%. Ar was used for stabilizing the discharge owing to the difficulty encountered in igniting and obtaining a stable discharge with only $\mathrm{Ne}$ mixed with $\mathrm{C}_{2} \mathrm{H}_{2}$. At the higher pressure of $3.3 \mathrm{~Pa}$, the discharge was comparatively more stable; therefore, a lower fraction of $\operatorname{Ar}(15 \%)$ was used.

A pulsing unit (home-built) fed by an MDX $1 \mathrm{~K}$ direct current generator (Advanced Energy) was used as HiPIMS power source. The power source provided unipolar rectangular shaped negative voltage pulses with variable pulsing frequencies and pulse widths. Power to the cathode was supplied using a voltage pulse of $600 \mathrm{~Hz}$ and pulse on time of $25 \mu$ s which resulted in a duty cycle of $1.5 \%$. An average power of $42 \mathrm{~W}$ was used during all experiments. The power of $42 \mathrm{~W}$ was chosen after process optimization for a stable operation. The discharge voltage, $U_{D}$, and discharge current, $I_{D}$, were monitored and recorded on a Tektronix TDS2004B oscilloscope. For reference, plasma discharges using the same flow rates of $\mathrm{Ar}$ and $\mathrm{Ne}$ as specified in (1) and (2) but without $\mathrm{C}_{2} \mathrm{H}_{2}$ were obtained. Since partial pressure of $\mathrm{C}_{2} \mathrm{H}_{2}$ with $2 \%$ of the total pressure is very small $(0.04$ and $0.06 \mathrm{~Pa}$ for total working pressures of 2 and $3.3 \mathrm{~Pa}$, respectively), we therefore consider that the change in $\mathrm{Ar}$ and $\mathrm{Ne}$ fractions in terms of pressure for reference discharges change only slightly and hence can be regarded as the same. From these discharges, $U_{D}$ and $I_{D}$ were recorded, and plasma parameters (see Sec. II A) were measured.

\section{A. Plasma characterization}

The plasma parameters, plasma density and electron temperature, were determined by measuring current-voltage characteristics of the plasma discharges using a home-built Langmuir probe measurement setup. A thin, cylindrical tungsten wire encapsulated in a ceramic tube with a protruding probe tip of length $5 \mathrm{~mm}$ and diameter $125 \mu \mathrm{m}$ was used as the Langmuir probe. The probe was mounted through a side port of the chamber such that it was lengthwise parallel to the target surface. The distance between the target surface and the probe was kept fixed at $60 \mathrm{~mm}$, while the tip of the probe was positioned at the center axis of the magnetron 
during the measurements. The current-voltage characteristics were obtained by applying a bias potential (from -40 to $+20 \mathrm{~V}$ in steps of $0.02 \mathrm{~V}$ ) to the probe and recording the current drawn from the plasma. In order to take into account the temporal variation associated with the pulsed nature of the HiPIMS discharge, a time resolved current, synchronized with the cathode voltage pulse, was measured. The current was recorded in 500 time-steps each with an interval of $320 \mathrm{~ns}$, giving a time-resolved current measured over a total time of $160 \mu \mathrm{s}$ after the pulse initiation. A current-voltage characteristic curve was constructed for each time step which was used for the determination of the EEDF (denoted as $g_{e}$ ) using the Druyvesteyn formula ${ }^{23}$

$$
g_{e}=\frac{2 m}{e^{2} A_{p r}}\left(\frac{2 e U}{m}\right)^{1 / 2} \frac{d^{2} I_{e}}{d U^{2}}
$$

where $A_{p r}$ is the area of the probe, $m$ and $e$ are the mass and charge of an electron, respectively, and $I_{e}$ is the electron current that is extracted from the measured probe current. $U$ is the probe potential, which is defined with respect to the plasma potential $\left(U_{p l}\right)$ and probe bias potential $\left(U_{p r}\right)$ as $U=U_{p l}-U_{p r}$. It should be noted that Eq. (1) involves a second order derivative of the measured current. This means that any noise present in the data is likely to be amplified during the differentiation, thus affecting the signal-to-noise ratio. A noise suppression of the measured current was therefore performed using Blackman window filtration. The details of this method can be found elsewhere. ${ }^{24}$

From the EEDF, the electron density, $n_{e}$, was determined as

$$
n_{e}=\int_{0}^{\infty} g_{e}(E) d E,
$$

whereas effective electron temperature, $T_{\text {eff }}$, was determined via the average electron energy, $E_{\text {avg }}$

$$
E_{\text {avg }}=\frac{1}{n_{e}} \int_{0}^{\infty} E g_{e}(E) d E
$$

using the relation

$$
T_{\text {eff }}=\frac{2}{3} E_{\text {avg }} .
$$

\section{B. Film synthesis and characterization}

Films were deposited under the two conditions [(1) and (2)] described above on single crystalline Si (100) substrates mounted on a water cooled stationary substrate holder placed at a distance of $60 \mathrm{~mm}$ from the target surface. Prior to depositions, the substrates were ultrasonically cleaned using acetone and isopropanol for $5 \mathrm{~min}$ each and blow dried using dry nitrogen. Plasma etching for removing native oxide from the surface of the substrates was performed in a pure $\mathrm{Ar}$ ambient at $4 \mathrm{~Pa}$ by applying a $600 \mathrm{~V}, 100 \mathrm{kHz}, 10 \mu$ s negative pulsed signal to the substrate holder. During the film deposition, the incident energy of the depositing species was controlled by applying a negative pulsed bias voltage $\left(U_{B}\right)$ signal to the substrate holder. The operation frequency of the voltage signal was $100 \mathrm{kHz}$, whereas the range of $U_{B}$ was chosen from floating potential, $\mathrm{U}_{\mathrm{fl}}(\sim-20 \mathrm{~V})$, to $200 \mathrm{~V}$. Ion energy is expressed by $U_{B}$ under the assumption of: ion energy $=e U_{B}$. The range of $U_{B}$ from $\mathrm{U}_{\mathrm{fl}}$ to $200 \mathrm{~V}$ thus corresponds to the range of ion energy from $\mathrm{eU}_{\mathrm{fl}}$ to $200 \mathrm{eV}$.

Mass densities of the resulting films were determined by performing $\mathrm{x}$-ray reflectometry (XRR) measurements using $\mathrm{Cu}-\mathrm{K}_{\alpha}(\lambda=0.15406 \mathrm{~nm})$ monochromatic radiation. From the measured XRR curve, the critical angle, $\theta_{\mathrm{c}}$, for the total external reflection was obtained, which was used to calculate the mass density. ${ }^{5}$ A simulated curve was generated using the X'pert reflectivity program ${ }^{25}$ and was fitted to the measured curve to obtain film thickness as well as to verify the calculated mass density. $\mathrm{H}$ content of the films was determined by employing a time-of-flight elastic recoil detection analysis setup using a $32 \mathrm{MeV}^{127} \mathrm{I}^{8+}$ beam. The incident angle of the beam with respect to the surface normal was chosen as $67.5^{\circ}$, while the detector was placed at a recoil angle of $45^{\circ}$. A detailed description of the experimental setup can be found elsewhere. ${ }^{26,27}$ For the analysis, a reference sample with known $\mathrm{H}$ content was used for calibration of the data. Film hardness was measured using a nanoindenter (UMIS-2000, Fischer-Cripps Laboratories) by employing a Berkovich shaped diamond tip. The hardness values were obtained from the indentation data using the Oliver-Pharr method. ${ }^{28}$ Film stress was measured ex situ using a laser-based wafer-curvature method by employing a multibeam optical stress sensor (k-Space Associates, Inc.). For these measurements, films were deposited on $100 \pm 20 \mu$ m thick Si (100) substrates, and the curvature of the substrate was measured before and after the film deposition. The stress of the film was calculated from the changes in the substrate curvature by using a modified Stoney equation. ${ }^{29,30}$

In order to investigate the bonding properties of the resulting films, Raman spectroscopy was performed using a Renishaw inVia Raman microscope equipped with an Ar laser of wavelength $514.5 \mathrm{~nm}$. Care was taken to avoid sample damage from the laser exposure, which was $40 \mu \mathrm{W}$ for $15 \mathrm{~s}$. Two Gaussian peak shapes were fitted to $950-1800 \mathrm{~cm}^{-1}$ region, and a linearly increasing background was subtracted.

\section{RESULTS AND DISCUSSION}

\section{A. Plasma properties}

Discharge voltage and current waveforms from a $2 \%$ $\mathrm{C}_{2} \mathrm{H}_{2}$ discharge operated at 3.3 Pa are presented in Fig. 1(a). Discharges operated using other gas phase composition and pressures show similar shape of voltage (not shown here) and current waveforms [Fig. 1(b)].

Overall, lower values of $U_{D}$ (720 and $632 \mathrm{~V}$ at 2 and 3.3 Pa, respectively) were obtained for the $2 \% \mathrm{C}_{2} \mathrm{H}_{2}$ discharges as compared to those of the $0 \% \mathrm{C}_{2} \mathrm{H}_{2}$ (752 and $680 \mathrm{~V}$ at 2 and $3.3 \mathrm{~Pa}$, respectively). The changes in $U_{D}$ levels are in accordance with the changes in $I_{D}$ since the average power for the discharges was kept constant. Moreover, as seen in Fig. 1(b), the discharge operated in pure inert gas ambient $\left(0 \% \mathrm{C}_{2} \mathrm{H}_{2}\right)$ and at $2 \mathrm{~Pa}$ exhibits the smallest peak 
value of $I_{D}(\sim 13 \mathrm{~A})$ whereas the discharge containing $\mathrm{C}_{2} \mathrm{H}_{2}$ and operated at $3.3 \mathrm{~Pa}$ exhibits the largest peak value of $I_{D}$ ( $\sim 25 \mathrm{~A})$. For both, $0 \% \mathrm{C}_{2} \mathrm{H}_{2}$ and $2 \% \mathrm{C}_{2} \mathrm{H}_{2}$, higher $I_{D}$ is measured at higher pressures. Larger peak values of $I_{D}$ when the gas atmosphere contains $\mathrm{C}_{2} \mathrm{H}_{2}$ at both 2 and $3.3 \mathrm{~Pa}$ indicate an increased positive ion flux to the cathode and/or increased secondary electron emission at the target. Such discharge current behavior is supported by the reported discharge current characteristics for reactive and nonreactive HiPIMS processes $^{31-34}$ and is believed to be related to strong recycling of process gas ions as the reactive gas flow increases. ${ }^{32-35}$

EEDFs for different discharges are presented in Fig. 2 whereas electron density, $n_{e}$, and effective electron temperature, $T_{\text {eff }}$, obtained from the EEDFs are presented in Table I. It should be noted here that due to high noise levels, reliable conclusions from the probe measurements could not be drawn during the pulse-on time. Therefore, the EEDFs recorded during pulse-off time; at $60 \mu \mathrm{s}$ after the pulse initiation, i.e., $35 \mu$ s after the pulse-off, are presented here. For $0 \% \mathrm{C}_{2} \mathrm{H}_{2}$, an increased pressure from 2 to $3.3 \mathrm{~Pa}$ does not yield an appreciable change in the EEDFs (Fig. 2) as well as in $n_{e}$ and $T_{\text {eff }}$ (Table I).

The EEDFs are relatively narrow as compared to those at $2 \% \mathrm{C}_{2} \mathrm{H}_{2}$ with their peaks around $1-2 \mathrm{eV}$. A small but distinct electron population from $\sim 20$ to $33 \mathrm{eV}$ is also observed. The distinct (low and high energy) electron populations in EEDFs are often encountered in HiPIMS discharges where the plasma electrons often exhibit bi-Maxwellian energy distributions. ${ }^{36}$
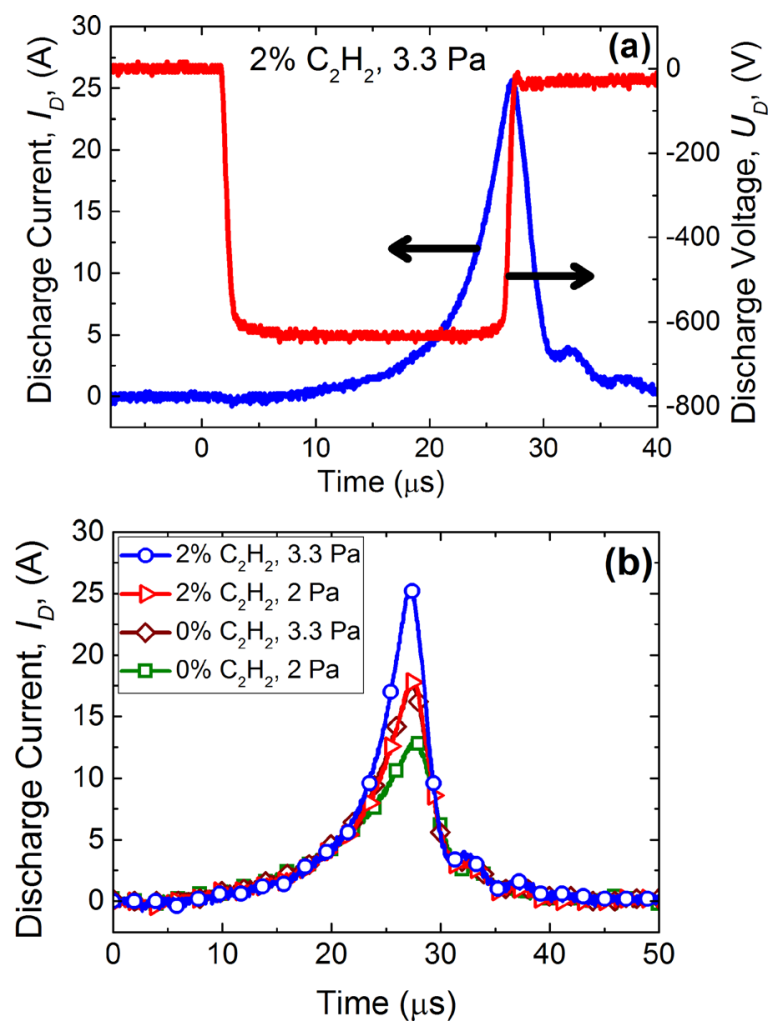

FIG. 1. (Color online) (a) Discharge voltage and current for $\mathrm{Ne}+\mathrm{Ar}$ discharge and (b) discharge currents for $\mathrm{Ne}+\mathrm{Ar} / \mathrm{C}_{2} \mathrm{H}_{2}$ discharges operated using $2 \% \mathrm{C}_{2} \mathrm{H}_{2}$ and at 2 and $3.3 \mathrm{~Pa}$. All discharges were operated using an average power of $42 \mathrm{~W}$.
For $2 \% \mathrm{C}_{2} \mathrm{H}_{2}$ and at $2 \mathrm{~Pa}$, the EEDF is broader as compared to the EEDF for $0 \% \mathrm{C}_{2} \mathrm{H}_{2}$ at the same pressure and exhibits a much more pronounced electron population in the energy range of $\sim 20-30 \mathrm{eV}$. This in turn results in a twofold increase of the mean electron temperature (from 1.4 to $3.3 \mathrm{eV}$ ) while $n_{e}$ remains almost unchanged. A further increase in the discharge pressure to 3.3 Pa leads to an even broader EEDF with majority of the electrons having energies between 2 and $15 \mathrm{eV}$ which corresponds to an $T_{\text {eff }}$ of $6.7 \mathrm{eV}$, i.e., two times higher than the value at $2 \mathrm{~Pa}$.

The results with regards to electron temperature are rather counterintuitive, since (1) higher pressures usually result in reduced electron temperature due to increased probability for ionizing collisions between electrons and gas atoms/molecules and (2) admixing $\mathrm{C}_{2} \mathrm{H}_{2}$ in the gas atmosphere is expected to further cool down the electrons through dissociation and ionization of hydrocarbon gas molecules. However, an increased electron temperature in a hydrocarbon discharge has been reported by Kim et al. ${ }^{37}$ where they measured $30 \%$ and $35 \%$ increase in electron temperatures, respectively, for an $\mathrm{Ar} / \mathrm{C}_{2} \mathrm{H}_{2}$ and $\mathrm{Ar} / \mathrm{CH}_{4}$ discharge as compared to pure Ar discharge. This increase in electron temperature can be understood as follows. The introduction of the reactive $\mathrm{C}_{2} \mathrm{H}_{2}$ gas into the HiPIMS process leads to the formation of hydrogen ions and hydrogen containing ions. For plasma discharges, various ionizing and dissociating interactions generating $\mathrm{C}_{\mathrm{x}} \mathrm{H}_{\mathrm{y}}{ }^{+}$ionized species and radicals have been reported. ${ }^{38-40}$ The electron impact dissociation of $\mathrm{C}_{2} \mathrm{H}_{2}\left(\mathrm{C}_{2} \mathrm{H}_{2}+e^{-} \rightarrow \mathrm{C}_{2} \mathrm{H}+\mathrm{H}+e^{-}\right)$has a low energy threshold $(\sim 7.5 \mathrm{eV})^{38}$ and is therefore likely a dominating interaction, which may result in a substantial amount of $\mathrm{C}_{2} \mathrm{H}$ radical generation. ${ }^{37,38}$ Electron impact ionization of $\mathrm{C}_{2} \mathrm{H}_{2}$, which has an energy threshold of $11.4 \mathrm{eV}$ giving $\mathrm{C}_{2} \mathrm{H}_{2}{ }^{+}$ions $\left(\mathrm{C}_{2} \mathrm{H}_{2}+e^{-} \rightarrow \mathrm{C}_{2} \mathrm{H}_{2}^{+}+2 e^{-}\right),{ }^{39}$ has also been found to be a dominating interaction, especially in high plasma density discharges. ${ }^{41,42}$ Other dissociative ionization processes giving $\mathrm{C}_{2} \mathrm{H}^{+}, \mathrm{C}_{2}{ }^{+}, \mathrm{H}^{+}$, and $\mathrm{C}^{+}$ions ${ }^{38,43}$ though have higher energy thresholds in the range of $16-21 \mathrm{eV},{ }^{39}$ may also be possible in a HiPIMS discharge. Therefore, in our $\mathrm{Ne}+\mathrm{Ar} / \mathrm{C}_{2} \mathrm{H}_{2}$ discharge, we expect that large amounts of $\mathrm{C}_{\mathrm{x}} \mathrm{H}_{\mathrm{y}}{ }^{+}$ions as well as $\mathrm{H}^{+}$ions are generated in addition to $\mathrm{C}^{+}, \mathrm{Ne}^{+}$, and $\mathrm{Ar}^{+}$ions. $\mathrm{A}$

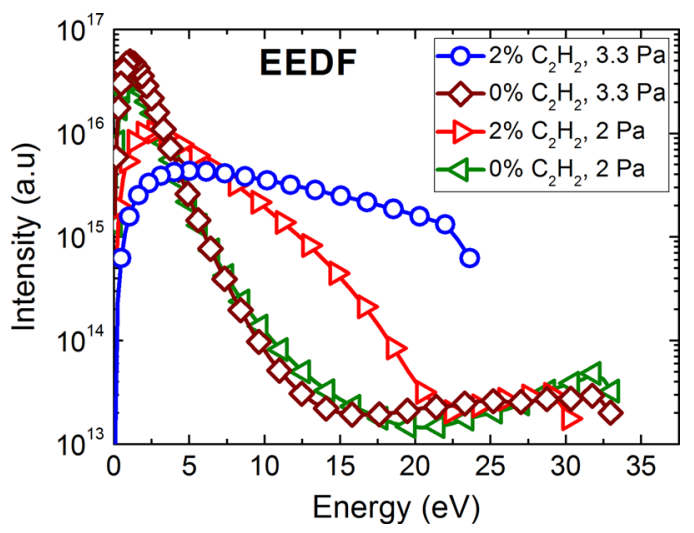

FIG. 2. (Color online) EEDFs for $\mathrm{Ne}+\mathrm{Ar}$ and $\mathrm{Ne}+\mathrm{Ar} / \mathrm{C}_{2} \mathrm{H}_{2}$ discharges operated at 2 and $3.3 \mathrm{~Pa}$ using an average power of $42 \mathrm{~W}$. The EEDFs were obtained from plasma current-voltage characteristics measured at $60 \mu$ s after the pulse initiation ( $35 \mu$ s after pulse-off). 
TABLE I. Plasma parameters determined from plasma current-voltage characteristics measured by using a Langmuir probe at $60 \mu$ s after the pulse initiation. The discharges were operated using an average power of $42 \mathrm{~W}$.

\begin{tabular}{lcc}
\hline \hline Process & $\begin{array}{c}\text { Electron density, } \\
n_{e}\left(\mathrm{~m}^{-3}\right)\end{array}$ & $\begin{array}{c}\text { Effective electron } \\
\text { temperature } T_{\text {eff }}(\mathrm{eV})\end{array}$ \\
\hline $\mathrm{Ne}+\mathrm{Ar}\left(0 \% \mathrm{C}_{2} \mathrm{H}_{2}\right), 2 \mathrm{~Pa}$ & $8.4 \times 10^{16}$ & 1.4 \\
$\mathrm{Ne}+\mathrm{Ar}\left(0 \% \mathrm{C}_{2} \mathrm{H}_{2}\right), 3.3 \mathrm{~Pa}$ & $1.1 \times 10^{17}$ & 1.3 \\
$\mathrm{Ne}+\mathrm{Ar}\left(2 \% \mathrm{C}_{2} \mathrm{H}_{2}\right), 2 \mathrm{~Pa}$ & $6.4 \times 10^{16}$ & 3.3 \\
$\mathrm{Ne}+\mathrm{Ar}\left(2 \% \mathrm{C}_{2} \mathrm{H}_{2}\right), 3.3 \mathrm{~Pa}$ & $6.4 \times 10^{16}$ & 6.7 \\
\hline \hline
\end{tabular}

fraction of these $\mathrm{C}_{\mathrm{x}} \mathrm{H}_{\mathrm{y}}{ }^{+}$ions and $\mathrm{H}^{+}$ions bombard the graphite target and modify the target composition. Woods et al. ${ }^{44}$ have shown that hydrogen ion bombardment increases the secondary electron emission yield (SEEY) of a graphite target. In their case, an increase of almost $30 \%$ was detected, but it depends on the amount of hydrogen implanted into the clean graphite target and the bombarding species. It is therefore likely that qualitatively the same trend holds true also in the present HiPIMS case, which also explains the increase in the recorded discharge current when adding $\mathrm{C}_{2} \mathrm{H}_{2}$ [Fig. 1(b)]. Furthermore, the increased SEEY results in more hot electrons being injected into the volume plasma, since the secondary electrons are accelerated over the cathode sheath potential, which typically is close to the full discharge voltage of about $600-700 \mathrm{~V}$ in the present discharges. As a result, the EEDF is broadened toward higher energies, as seen from the Langmuir probe measurements reported in Fig. 2.

In addition, the increase in $T_{\text {eff }}$ with increasing pressure is likely due to the increased $\mathrm{Ne}$ fraction in the total gas mixture, going from $62 \% \mathrm{Ne}$ at $2 \mathrm{~Pa}$ to $83 \% \mathrm{Ne}$ at $3.3 \mathrm{~Pa}$. The electron energy has to be sufficiently high to sustain the plasma, which requires more energetic electrons when the $\mathrm{Ne}$ content is increased, since $\mathrm{Ne}$ has a higher first ionization potential compared to $\operatorname{Ar}\left(E_{i, \mathrm{Ne}}=21.56 \mathrm{eV}\right.$ and $\left.E_{i, \mathrm{Ar}}=15.76 \mathrm{eV}\right)$. Such a strong increase in $T_{\text {eff }}$ has also been reported by Haase et al. ${ }^{45}$ when comparing a pure Ar discharge to a pure Ne discharge in magnetron sputtering.

\section{B. Film properties}

Figure 3 presents mass density, $\mathrm{H}$ content, and hardness of the resulting films as a function of the negative substrate bias potential, $U_{B}$. The films were grown at the discharge conditions described in Sec. II B. With an increase in $U_{B}$, the mass density [Fig. 3(a)] and hardness [Fig. 3(c)] exhibit an increase while the $\mathrm{H}$ content decreases [Fig. 3(b)]. The increase in mass density and hardness can be attributed to subsurface implantation (also known as subplantation) ${ }^{2}$ of the ionized depositing species. Moreover, when synthesized from hydrocarbon based discharges, carbon films are expected to contain large amounts of $\mathrm{H}$ due to deposition of $\mathrm{C}_{\mathrm{x}} \mathrm{H}_{\mathrm{y}}$ species giving rise to $\mathrm{C}-\mathrm{H}$ bonds. Concurrently, the ion bombardment during the film growth, facilitated by $U_{B}$, may lead to $\mathrm{C}-\mathrm{H}$ bond breaking resulting in reduction of $\mathrm{H}$ content of the films. ${ }^{46,47}$ The competition between the $\mathrm{H}$ incorporation and removal mechanisms outlined above may

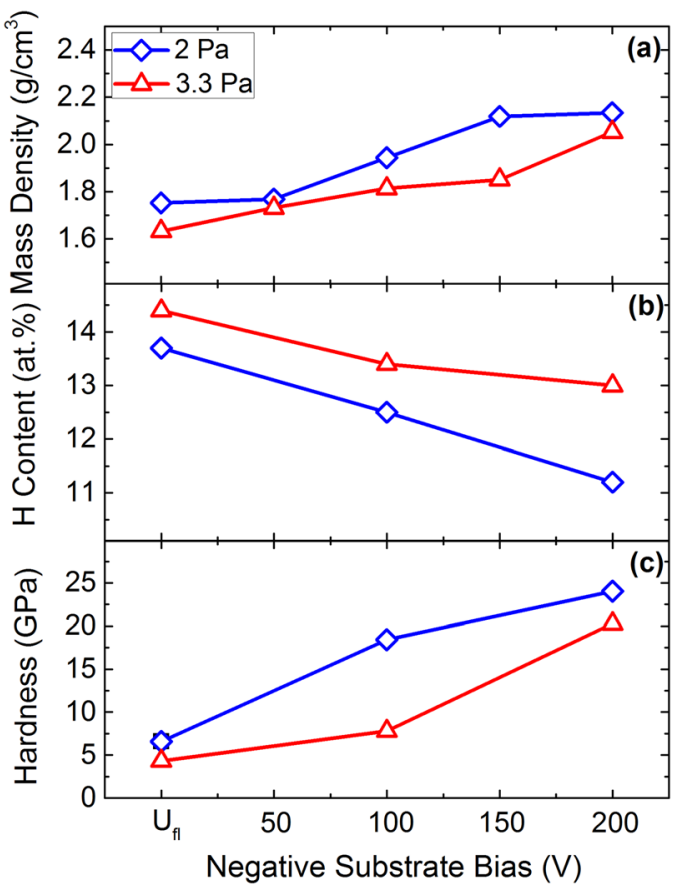

Fig. 3. (Color online) (a) Mass density, (b) $\mathrm{H}$ content (at. \%) and (c) film hardness as a function of $U_{B}$ of the films grown using $\mathrm{Ne}+\mathrm{Ar} / \mathrm{C}_{2} \mathrm{H}_{2}$ process operated at 2 and $3.3 \mathrm{~Pa}$ and an average power of $42 \mathrm{~W}$. Panels (a)-(c) use the same color and symbol coding. The lines are guide for the eye.

also explain the increase in density as well as the decrease in $\mathrm{H}$ content observed in Fig. 3.

It is also evident that there is no appreciable difference between the density and hardness values at 2 and $3.3 \mathrm{~Pa}$ except for $U_{B}=150 \mathrm{~V}$ where a higher mass density and for $U_{B}=100 \mathrm{~V}$ where a higher hardness are obtained for the $2 \mathrm{~Pa}$ case. However, films grown at a higher pressure of 3.3 $\mathrm{Pa}$ contain higher amount of $\mathrm{H}$ as compared to those grown at $2 \mathrm{~Pa}$. This is found for all $U_{B}$ values used. Higher $\mathrm{H}$ content of the films at higher pressure of $3.3 \mathrm{~Pa}$ could be a consequence of lower bombardment energies of the deposition species due to more collisions in the sheath at the higher pressure of 3.3 Pa. Slight differences in mass densities and hardness at 2 and $3.3 \mathrm{~Pa}$ are consistent with the changes in the $\mathrm{H}$ content of the films at these pressures. Overall, the $\mathrm{H}$ content remained under 15 at. \% while the lowest amount of $\mathrm{H}$ (close to 11 at. \%) is found for the film grown at $2 \mathrm{~Pa}$ using maximum value of $U_{B}$, i.e., $200 \mathrm{~V}$. Hardness of the films spans a wide range from about 5 to $25 \mathrm{GPa}$ for the range of $U_{B}$ used. The maximum hardness is about $25 \mathrm{GPa}$, which is obtained for the film grown at $2 \mathrm{~Pa}$ using $U_{B}=200 \mathrm{~V}$.

Increased density and hardness with an increased $U_{B}$ can either be attributed to an increase in the fraction of $\mathrm{C}-\mathrm{C} \mathrm{sp}^{3}$ bonds created via implantation of hyperthermal $\mathrm{C}$ ions and/ or to an enhanced $\mathrm{H}$ removal via $\mathrm{C}-\mathrm{H}$ bond breaking. In order to elucidate the bonding configuration of the films, Raman spectroscopic measurements were performed, and the results are presented in Fig. 4. The Raman measurements revealed two broad peaks typical for amorphous carbon films in the region of $950-1800 \mathrm{~cm}^{-1}$. The peak centered around $1535-1540 \mathrm{~cm}^{-1}$ was assigned to the graphitic peak (G- 
peak), whereas the peak centered around $1330-1360 \mathrm{~cm}^{-1}$ was assigned to the disorder peak (D-peak). ${ }^{48}$ Figure 4 shows the evolution of intensity (height) ratio of the $\mathrm{D}$ and $\mathrm{G}$ peaks $[\mathrm{I}(\mathrm{D}) / \mathrm{I}(\mathrm{G})]$ and the full-width at half maximum of G-peak (G-width) with respect to $U_{B}$. The $\mathrm{I}(\mathrm{D}) / \mathrm{I}(\mathrm{G})$ ratio is proportional to the $\mathrm{sp}^{2}$ cluster size and inversely proportional to the total $(\mathrm{C}-\mathrm{H}$ and $\mathrm{C}-\mathrm{C}) \mathrm{sp}^{3}$ content. ${ }^{49} \mathrm{It}$ is found that the $\mathrm{I}(\mathrm{D}) / \mathrm{I}(\mathrm{G})$ is essentially constant with respect to the changes in $U_{B}$ [Fig. 4(a)] for $2 \mathrm{~Pa}$, whereas a slight increase in I(D)/ $\mathrm{I}(\mathrm{G})$ with an increase in $U_{B}$ is observed at the higher pressure of 3.3 Pa. A difference between the $\mathrm{I}(\mathrm{D}) / \mathrm{I}(\mathrm{G})$ ratio for the two pressures is seen for $U_{B}$ values from $U_{\mathrm{fl}}$ to $100 \mathrm{~V}$, whereas at $U_{B}=150 \mathrm{~V}$ and $U_{B}=200 \mathrm{~V}$, the ratio is roughly the same for the two pressures.

At $2 \mathrm{~Pa}$, the essentially unchanged $\mathrm{I}(\mathrm{D}) / \mathrm{I}(\mathrm{G})$ ratio with respect to $U_{B}$ suggests that no major changes in the total $\mathrm{sp}^{3}$ content occurred. However, since the $\mathrm{H}$ content decreased with increased $U_{B}$ [Fig. 3(b)], it can be concluded that the $\mathrm{C}-\mathrm{H} \mathrm{sp}{ }^{3}$ content is likewise decreased, i.e., the $\mathrm{C}-\mathrm{C} \mathrm{sp}{ }^{3}$ content must increase. This is consistent with the increase observed in film hardness [Fig. 3(c)] with an increase in $U_{B}$. Moreover, Fig. 4(b) shows an overall increase in the G-width from $\sim 170$ to $\sim 200 \mathrm{~cm}^{-1}$ in the investigated $U_{B}$ range at both 2 and 3.3 Pa. This increase is associated with bond length and bond angle disorder in a-C films. ${ }^{48,50}$ As discussed above, in our films an overall higher $\mathrm{sp}^{3}$ content is expected with an increase in $U_{B}$. This in turn would cause the C-C $\mathrm{sp}^{2}$ clusters to reduce in size making them more stressed, ${ }^{50}$ which is reflected by the increase in G-width. This is consistent with the measured compressive stress in the films which were found to increase with an increase in $U_{B}$ (not shown here). The overall stress levels, however, were low and did not exceed $0.5 \mathrm{GPa}$, and the films with thickness in the order of $1 \mu \mathrm{m}$ were possible to be synthesized without any adhesion layer.

In order to elucidate the effect of admixing $\mathrm{Ne}$ in $\mathrm{Ar} /$ $\mathrm{C}_{2} \mathrm{H}_{2}$ discharge, in Figs. 5 and 6, we compare the properties

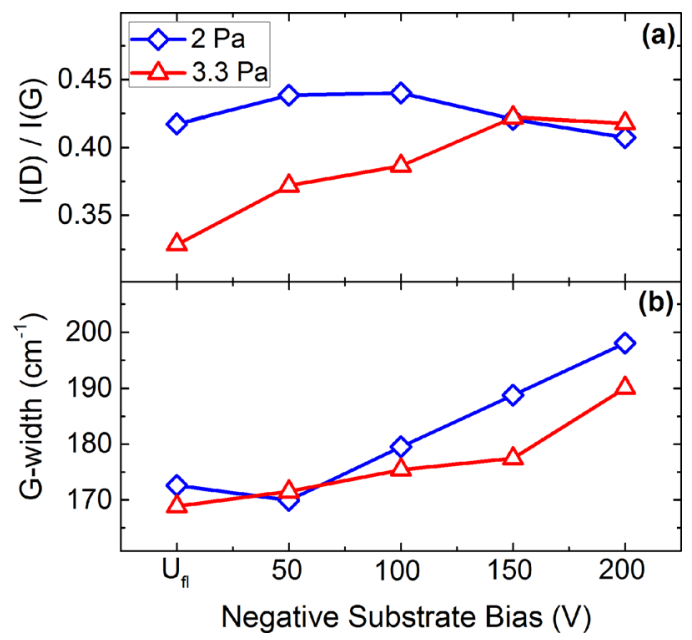

FIG. 4. (Color online) Raman parameters; (a) (intensity) ratio of D and G peaks and (b) G-peak width as a function of $U_{B}$ of the films grown at 2 and $3.3 \mathrm{~Pa}$ of operating pressures and an average power of $42 \mathrm{~W}$. Both panels (a) and (b) use the same color and symbol coding. The lines are guide for the eye only. of the films synthesized using $\mathrm{Ne}+\mathrm{Ar} / \mathrm{C}_{2} \mathrm{H}_{2}$ process (only from $2 \mathrm{~Pa}$ ) with the films synthesized in our earlier works under similar process conditions: films synthesized using $\mathrm{Ar} /$ $\mathrm{C}_{2} \mathrm{H}_{2}$, pure $\mathrm{Ar}$ and $\mathrm{Ne}+\mathrm{Ar}$ based HiPIMS discharges. ${ }^{21,22}$ Figure 5 shows mass densities of the films resulting from different processes. For the discharge processes operated without $\mathrm{C}_{2} \mathrm{H}_{2}$, the mass densities are higher as compared to those operated using $2 \% \mathrm{C}_{2} \mathrm{H}_{2}$. This is a direct consequence of $\mathrm{H}$ incorporation into the films that lowers the density and film hardness when films are synthesized using hydrocarbon based discharges. ${ }^{47}$ Interestingly, the mass densities exhibit different behavior with regards to admixing $\mathrm{Ne}$ for the discharges operated with and without $\mathrm{C}_{2} \mathrm{H}_{2}$. With no $\mathrm{C}_{2} \mathrm{H}_{2}$, admixing $\mathrm{Ne}$ into $\mathrm{Ar}$ ambient entails higher mass densities that can be attributed to an increased $\mathrm{C}$ ionization via electron temperature enhancement when using $\mathrm{Ne}$. An increased ionization of sputtered $\mathrm{C}$ eventually leads to denser a-C films.

For $\mathrm{C}_{2} \mathrm{H}_{2}$ containing discharges, admixing $\mathrm{Ne}$ to $\mathrm{Ar} / \mathrm{C}_{2} \mathrm{H}_{2}$ does not yield any appreciable differences in mass densities. However, a closer inspection of the $\mathrm{H}$ contents and hardness values of the corresponding films in Fig. 6 reveals that the films grown using Ne-based discharge contain higher amount of $\mathrm{H}$ whereas the lowest and highest achievable film hardness values are comparable. A higher $\mathrm{H}$ incorporation in the films indicates that the plasma-chemical interactions produce increased dissociation of $\mathrm{C}_{2} \mathrm{H}_{2}$ in $\mathrm{Ne}$ containing process as compared to Ar. This could be due to higher electron temperatures that have been reported ${ }^{21}$ when a discharge is operated using Ne. However, with an increased H content, one expects a reduced mass density and film hardness which is not observed in our case. This could be a consequence of either a different densification route or a different chemical composition of the deposition flux for $\mathrm{Ne}+\mathrm{Ar} / \mathrm{C}_{2} \mathrm{H}_{2}$ grown films as compared to $\mathrm{Ar} / \mathrm{C}_{2} \mathrm{H}_{2}$. Densification of DLC:H films may occur through either $\mathrm{H}$ removal and subsequent bond rearrangement leading to $\mathrm{C}-\mathrm{C} \mathrm{sp}{ }^{2}$ bonds or through subplantation of ionized deposition species giving rise to $\mathrm{C}-\mathrm{C} \mathrm{sp} \mathrm{sp}^{3}$ bonds. The latter is observed for ta-C:H films where, as compared to a-C:H films, high hardness and mass densities are obtained with substantially high amount of $\mathrm{H}(20 \%-30 \%)$ present in the films. ${ }^{5,51,52}$

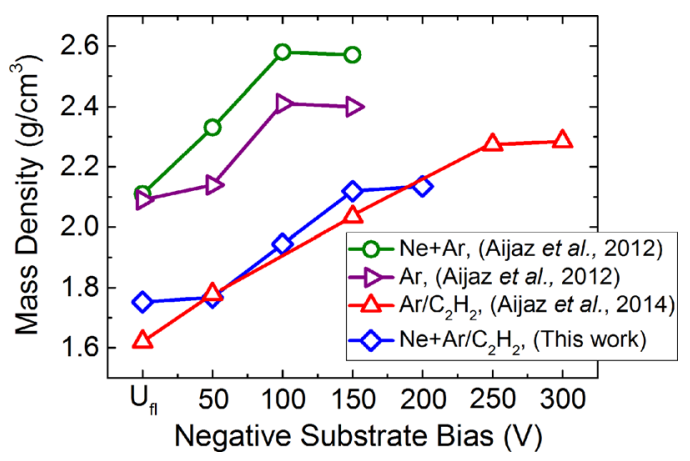

FIG. 5. (Color online) Mass density as a function of $U_{B}$ of the films grown at $2 \mathrm{~Pa}$ using $\mathrm{Ne}+\mathrm{Ar}$ (Ref. 21), pure $\mathrm{Ar}$ (Ref. 21), $\mathrm{Ar} / \mathrm{C}_{2} \mathrm{H}_{2}$ (Ref. 22), and $\mathrm{Ne}+\mathrm{Ar} / \mathrm{C}_{2} \mathrm{H}_{2}$ discharges. The lines are guide for the eye only. 


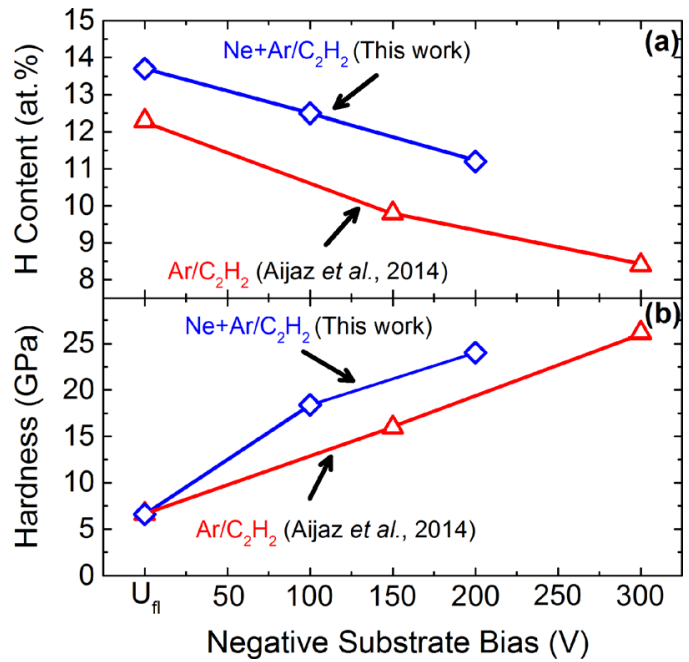

FIG. 6. (Color online) (a) $\mathrm{H}$ content and (b) film hardness as a function of $U_{B}$ of the films grown at $2 \mathrm{~Pa}$ using $\mathrm{Ar} / \mathrm{C}_{2} \mathrm{H}_{2}$ (Ref. 22) and $\mathrm{Ne}+\mathrm{Ar} / \mathrm{C}_{2} \mathrm{H}_{2}$ discharges. The lines are guide for the eye only.

\section{CONCLUSIONS}

DLC:H thin films have been synthesized using a $\mathrm{Ne}+\mathrm{Ar} /$ $\mathrm{C}_{2} \mathrm{H}_{2}$ based HiPIMS discharge process. The discharge properties show that $\mathrm{C}_{2} \mathrm{H}_{2}$ containing discharges exhibit higher electron temperatures as compared to $\mathrm{Ne}+\mathrm{Ar}$ discharges. The structural and mechanical properties of the resulting films are found to be governed by the chemistry and energy of the deposition flux. Energetic ion bombardment during the film growth, manipulated by the substrate bias potential, leads to DLC:H films with $\mathrm{H}$ content as low as $\sim 11 \%$ together with high film hardness that is reaching up to $\sim 25 \mathrm{GPa}$. The films exhibit low stresses (below $0.5 \mathrm{GPa}$ ) that makes it possible to synthesize films with a thickness exceeding $1 \mu \mathrm{m}$. The film densification and subsequent changes in the mechanical properties are affected mainly by $\mathrm{H}$ removal via ion bombardment.

\section{ACKNOWLEDGMENTS}

A.A. and U.H. gratefully acknowledge the financial support provided by the Swedish Research Council (VR) through the Contract Nos. 621-2011-4280 and 621-2014-4882. A.A., T.K., D.L. and U.H. acknowledge the financial support from MEra.Net (TANDEM). K.S. should like to acknowledge financial support from Linköping University through the "LiU Research Fellows Program, 2011-2015" and the "LiU Career Contract (Dnr-LiU-2015-01510), 2015-2020.” S.L. would like to acknowledge the Danish Council for Independent Research, Technology and Production Sciences for financial support. The authors are also grateful for access to the Tandem Laboratory at Uppsala University. European Collaboration in Science and Technology (COST Action MP0804) is gratefully acknowledged for stimulating discussions.

${ }^{1}$ J. Robertson, Diamond Relat. Mater. 4, 297 (1995).

${ }^{2}$ J. Robertson, Mater. Sci. Eng. R 37, 129 (2002).
${ }^{3}$ J. K. Luo, Y. Q. Fu, H. R. Le, J. A. Williams, S. M. Spearing, and W. I. Milne, J. Micromech. Microeng. 17, S147 (2007).

${ }^{4}$ G. Dearnaley and J. H. Arps, Surf. Coat. Technol. 200, 2518 (2005).

${ }^{5}$ A. C. Ferrari, A. Libassi, B. K. Tanner, V. Stolojan, J. Yuan, L. M. Brown, S. E. Rodil, and B. Kleinsorge, Phys. Rev. B 62, 11089 (2000).

${ }^{6}$ G. A. Abbas, S. S. Roy, P. Papakonstantinou, and J. A. McLaughlin, Carbon 43, 303 (2005).

${ }^{7}$ P. Patsalas, S. Kaziannis, C. Kosmidis, D. Papadimitriou, G. Abadias, and G. A. Evangelakis, J. Appl. Phys. 101, 124903 (2007).

${ }^{8}$ M. Pervolaraki, P. Komninou, J. Kioseoglou, A. Othonos, and J. Giapintzakis, Appl. Surf. Sci. 278, 101 (2013).

${ }^{9}$ M. Samuelsson, K. Sarakinos, H. Högberg, E. Lewin, U. Jansson, B. Wälivaara, H. Ljungcrantz, and U. Helmersson, Surf. Coat. Technol. 206, 2396 (2012).

${ }^{10}$ U. Helmersson, M. Lattemann, J. Bohlmark, A. P. Ehiasarian, and J. T. Gudmundsson, Thin Solid Films 513, 1 (2006).

${ }^{11}$ D. Lundin and K. Sarakinos, J. Mater. Res. 27, 780 (2012).

${ }^{12}$ J. T. Gudmundsson, N. Brenning, D. Lundin, and U. Helmersson, J. Vac. Sci. Technol., A 30, 030801 (2012).

${ }^{13}$ K. Sarakinos, A. Braun, C. Zilkens, S. Mráz, J. M. Schneider, H. Zoubos, and P. Patsalas, Surf. Coat. Technol. 206, 2706 (2012).

${ }^{14}$ B. M. Dekoven et al., 46th Annual Technical Conference Proceedings (2003), p. 158.

${ }^{15}$ M. Lattemann, B. Abendroth, A. Moafi, D. G. McCulloch, and D. R. McKenzie, Diamond Relat. Mater. 20, 68 (2011).

${ }^{16}$ J. Lin, W. D. Sproul, R. Wei, and R. Chistyakov, Surf. Coat. Technol. 258, 1212 (2014).

${ }^{17}$ S. Nakao, K. Yukimura, S. Nakano, and H. Ogiso, IEEE Trans. Plasma Sci. 41, 1819 (2013).

${ }^{18}$ T. Kimura and H. Kamata, Jpn. J. Appl. Phys., Part 1 55, 07LE02 (2016).

${ }^{19}$ J. Bohlmark, J. Alami, C. Christou, A. P. Ehiasarian, and U. Helmersson, J. Vac. Sci. Technol., A 23, 18 (2005).

${ }^{20}$ T. Kubart, M. Čada, D. Lundin, and Z. Hubička, Surf. Coat. Technol. 238, 152 (2014).

${ }^{21}$ A. Aijaz, K. Sarakinos, D. Lundin, N. Brenning, and U. Helmersson, Diamond Relat. Mater. 23, 1 (2012).

${ }^{22}$ A. Aijaz, K. Sarakinos, M. Raza, J. Jensen, and U. Helmersson, Diamond Relat. Mater. 44, 117 (2014).

${ }^{23}$ M. A. Lieberman, Principles of Plasma Discharges and Materials Processing, 2nd ed. (Willey, Hoboken, NJ, 2005).

${ }^{24}$ F. Magnus and J. T. Gudmundsson, Rev. Sci. Instrum. 79, 073503 (2008).

${ }^{25}$ PANalytical, X'Pert Reflectivity (PANalytical B.V., Almelo, The Netherlands, 2012).

${ }^{26}$ J. Jensen, D. Martin, A. Surpi, and T. Kubart, Nucl. Instrum. Methods Phys. Res., Sect. B 268, 1893 (2010).

${ }^{27}$ H. J. Whitlow, G. Possnert, and C. S. Petersson, Nucl. Instrum. Methods Phys. Res., Sect. B 27, 448 (1987).

${ }^{28}$ W. C. Oliver and G. M. Pharr, J. Mater. Res. 7, 1564 (1992).

${ }^{29}$ G. G. Stoney, Proc. R. Soc. London, Ser. A 82, 172 (1909).

${ }^{30}$ G. C. A. M. Janssen, M. M. Abdalla, F. van Keulen, B. R. Pujada, and B. van Venrooy, Thin Solid Films 517, 1858 (2009).

${ }^{31}$ D. Lundin, N. Brenning, D. Jädernäs, P. Larsson, E. Wallin, M. Lattemann, M. A. Raadu, and U. Helmersson, Plasma Sources Sci. Technol. 18, 045008 (2009).

${ }^{32}$ F. Magnus, T. K. Tryggvason, S. Olafsson, and J. T. Gudmundsson, J. Vac. Sci. Technol., A 30, 050601 (2012).

${ }^{33}$ F. Magnus, O. B. Sveinsson, S. Olafsson, and J. T. Gudmundsson, J. Appl. Phys. 110, 083306 (2011).

${ }^{34}$ M. Aiempanakit, A. Aijaz, D. Lundin, U. Helmersson, and T. Kubart, J. Appl. Phys. 113, 133302 (2013).

${ }^{35}$ J. T. Gudmundsson, D. Lundin, N. Brenning, M. A. Raadu, C. Huo, and T. M. Minea, "An ionization region model of the reactive $\mathrm{Ar} / \mathrm{O}_{2}$ high power impulse magnetron sputtering discharge," Plasma Sources Sci. Technol. (submitted).

${ }^{36}$ J. T. Gudmundsson, J. Alami, and U. Helmersson, Surf. Coatings Technol. 161, 249 (2002).

${ }^{37}$ B. K. Kim and T. A. Grotjohn, Diamond Relat. Mater. 9, 37 (2000).

${ }^{38}$ J. Benedikt, J. Phys. D: Appl. Phys. 43, 043001 (2010).

${ }^{39}$ K. De Bleecker, A. Bogaerts, and W. Goedheer, Phys. Rev. E 73, 026405 (2006).

${ }^{40}$ Y. H. Cheng, Y. P. Wu, J. G. Chen, X. L. Qiao, C. S. Xie, B. K. Tay, S. P. Lau, and X. Shi, Surf. Coat. Technol. 135, 27 (2000). 
${ }^{41}$ M. Weiler, S. Sattel, T. Giessen, K. Jung, and H. Ehrhardt, Phys. Rev. B 53, 1594 (1996).

${ }^{42}$ A. Baby, C. M. O. Mahony, and P. D. Maguire, Plasma Sources Sci. Technol. 20, 015003 (2011).

${ }^{43}$ J. R. Doyle, J. Appl. Phys. 82, 4763 (1997).

${ }^{44}$ M. E. Woods, B. J. Hopkins, G. F. Matthews, G. M. McCracken, P. M. Sewell, and H. Fahrang, J. Phys. D: Appl. Phys. 20, 1136 (1987).

${ }^{45}$ F. Haase, D. Lundin, S. Bornholdt, and H. Kersten, Contrib. Plasma Phys. 55, 701 (2015).

${ }^{46}$ W. Jacob, Thin Solid Films 326, 1 (1998).
${ }^{47}$ J. Benedikt, R. V. Woen, S. L. M. Van Mensfoort, V. Perina, J. Hong, and M. C. M. Van De Sanden, Diamond Relat. Mater. 12, 90 (2003).

${ }^{48}$ C. Casiraghi, A. C. Ferrari, and J. Robertson, Phys. Rev. B 72, 085401 (2005).

${ }^{49}$ M. A. Tamor and W. C. Vassell, J. Appl. Phys. 76, 3823 (1994).

${ }^{50}$ K. W. R. Gilkes, S. Prawer, K. W. Nugent, J. Robertson, H. S. Sands, Y. Lifshitz, and X. Shi, J. Appl. Phys. 87, 7283 (2000).

${ }^{51}$ M. Weiler, K. Lang, E. Li, and J. Robertson, Appl. Phys. Lett. 72, 1314 (1998).

${ }^{52}$ P. Koidl, C. Wild, B. Dischler, J. Wagner, and M. Ramsteiner, Mater. Sci. Forum 52-53, 41 (1990). 